\title{
Skill utilization and well-being: a cross-level story of day-to-day fluctuations and personal intrinsic values
}

Citation for published version (APA):

Van den Broeck, A., Schreurs, B. H. J., Günter, H., \& van Emmerik, I. H. (2015). Skill utilization and wellbeing: a cross-level story of day-to-day fluctuations and personal intrinsic values. Work and Stress, 29(3), 306-323. https://doi.org/10.1080/02678373.2015.1074955

Document status and date:

Published: 03/07/2015

DOI:

10.1080/02678373.2015.1074955

Document Version:

Publisher's PDF, also known as Version of record

Document license:

Taverne

\section{Please check the document version of this publication:}

- A submitted manuscript is the version of the article upon submission and before peer-review. There can be important differences between the submitted version and the official published version of record.

People interested in the research are advised to contact the author for the final version of the publication, or visit the DOI to the publisher's website.

- The final author version and the galley proof are versions of the publication after peer review.

- The final published version features the final layout of the paper including the volume, issue and page numbers.

Link to publication

\footnotetext{
General rights rights.

- You may freely distribute the URL identifying the publication in the public portal. please follow below link for the End User Agreement:

www.umlib.nl/taverne-license

Take down policy

If you believe that this document breaches copyright please contact us at:

repository@maastrichtuniversity.nl

providing details and we will investigate your claim.
}

Copyright and moral rights for the publications made accessible in the public portal are retained by the authors and/or other copyright owners and it is a condition of accessing publications that users recognise and abide by the legal requirements associated with these

- Users may download and print one copy of any publication from the public portal for the purpose of private study or research.

- You may not further distribute the material or use it for any profit-making activity or commercial gain

If the publication is distributed under the terms of Article $25 \mathrm{fa}$ of the Dutch Copyright Act, indicated by the "Taverne" license above, 


\title{
Skill utilization and well-being: a cross-level story of day-to-day fluctuations and personal intrinsic values
}

\author{
Anja Van den Broeck, Bert Schreurs, Hannes Guenter \& IJ. Hetty van \\ Emmerik
}

To cite this article: Anja Van den Broeck, Bert Schreurs, Hannes Guenter \& IJ. Hetty van Emmerik (2015) Skill utilization and well-being: a cross-level story of day-to-day fluctuations and personal intrinsic values, Work \& Stress, 29:3, 306-323, DOI: 10.1080/02678373.2015.1074955

To link to this article: https://doi.org/10.1080/02678373.2015.1074955

曲 Published online: 23 Sep 2015.

Submit your article to this journal ๘

Џll Article views: 468

View Crossmark data $\nearrow$

Citing articles: 13 View citing articles $\sqsubset \pi$ 


\title{
Skill utilization and well-being: a cross-level story of day-to- day fluctuations and personal intrinsic values
}

\author{
Anja Van den Broeck ${ }^{a, b}$, Bert Schreurs ${ }^{c}$, Hannes Guenter ${ }^{c}$ and IJ. Hetty van Emmerik ${ }^{c}$ \\ ${ }^{a}$ Human Relations Research Group, Faculty of Economics and Business, KU Leuven, Campus Brussels, Brussels, \\ Belgium; ${ }^{\mathrm{b} O p t e n t i a, ~ N o r t h ~ W e s t ~ U n i v e r s i t y, ~ V a n d e r b i j l p a r k ~ C a m p u s, ~ V a n d e r b i j l p a r k, ~ Z u i d ~ A f r i k a ; ~ ' D e p a r t m e n t ~}$ \\ of Organization and Strategy, Maastricht University School of Business and Economics, Maastricht, The \\ Netherlands
}

\begin{abstract}
The opportunity to use one's skills at work is an important prerequisite for employee well-being. Drawing on self-determination and personenvironment fit theory, this diary study aims to add to our understanding of this important phenomenon in two ways. Firstly, we examine the associations of within-subject daily variations in skill utilization with well-being. Secondly, we model work value orientation as a between-subject factor that moderates this withinsubject relationship. Specifically, we advocate that daily skill utilization is more beneficial (in terms of more daily work engagement and less daily emotional exhaustion) for employees holding predominantly intrinsic (i.e. self-development, community contribution) as opposed to extrinsic (i.e. financial success, status) values. Results of multilevel modelling using diary data from 99 service workers over five working days, supported the assumption that daily skill utilization was positively related to daily work engagement, particularly among employees holding a predominantly intrinsic work value orientation. Contrary to our expectations, daily skill utilization was unrelated to daily exhaustion, both for employees holding high and low intrinsic values. The discussion highlights the importance of, and employees' receptiveness to, variations in beneficial working conditions.
\end{abstract}

\section{ARTICLE HISTORY}

Received 31 January 2013

Revised 24 September 2014

Accepted 13 October 2014

\section{KEYWORDS}

Skill utilization; well-being; diary study; intrinsic and extrinsic values; work engagement

\section{Introduction}

What can employers do to improve the well-being of their employees? One piece of oftenheard advice is to let employees do what they are good at and let them practice their skills, that is to say, to provide them with opportunities for skill utilization (Karasek, 1979). Employees who are able to use their skills have been shown to report higher level of well-being, to be more satisfied, more committed, and more productive (e.g. Van Ruysseveldt \& Van Dijke, 2011). Not all studies, however, supported this finding (e.g. Akerboom \& Maes, 2006), which suggests that the nature of the relationship of skill utilization with well-being is more complex than originally thought.

The present study aims to increase our understanding of the relationship between skill utilization and well-being. Specifically, we draw on self-determination theory (SDT; Deci 
\& Ryan, 2000) and person-environment fit theory (P-E fit; Kristof-Brown, Zimmerman, \& Johnson, 2005) to examine whether employees holding predominantly intrinsic work values benefit more from daily opportunities to utilize their skills than employees holding predominantly extrinsic work values. We investigate these benefits in terms of two potential well-being outcomes: work engagement and emotional exhaustion.

We make two specific contributions to the literature. Firstly, we build a within-subject model linking daily skill utilization to daily well-being at work. From a theoretical point of view, this approach is valuable, as it examines the extent to which the ups and downs across the workweek in well-being have to do with variations in skill discretion. From a methodological point of view, a within-subject design limits retrospective bias as the measurements closely follow employees' experience, and captures the dynamics in a real life context (Bolger, Davis, \& Rafaeli, 2003).

Secondly, this study fills a gap in the literature by using a contingency perspective to examine the effects of skill utilization. Specifically, we study how between-individual differences in employees' trait-like characteristics influence the relationship between daily skill utilization and well-being. In line with SDT, we distinguish between intrinsic (e.g. personal growth) and extrinsic work values (e.g. materialism). In line with personenvironment fit theory, we then argue that the beneficial effects of daily skill utilization are more pronounced for employees holding predominantly intrinsic work values, since these employees will experience enhanced levels of fit when offered such opportunities.

In this study, we thus tie in with the recent developments in occupational health psychology and scrutinize how between and within-subject factors jointly influence employees' experiences (Ohly, Sonnentag, Niessen, \& Zapf, 2010). In the following sections, we discuss the rationale for these expectations.

\section{Associations of skill utilization with well-being}

Skill utilization refers to an employee's opportunity to use specific job skills in the working process (Hausser, Mojzisch, Niesel, \& Schulz-Hardt, 2010). It has a prominent place in various occupational stress models. In the job-demand control model (JDC model; Karasek, 1979), for example, skill utilization is considered one of the core components of control, and it is therefore able to increase motivation and to reduce strain. Along similar lines, skill utilization is conceptualized as a job resource in the job demandsresources model (JD-R model; Demerouti, Bakker, Nachreiner, \& Schaufeli, 2001). Job resources reduce job demands and their associated physiological and psychological costs, assist in achieving work goals and stimulate personal growth and learning. Skill utilization is therefore understood to be motivating and to relate positively to work engagement. Additionally, JD-R scholars argue that job resources may decrease exhaustion either directly (e.g. Schaufeli \& Bakker, 2004) or by buffering the effects of job demands (Bakker, Demerouti, \& Sanz-Vergel, 2014).

The arguments of the JDC and JD-R models are consistent with broader theoretical frameworks such as the conservation of resources theory (COR; Hobfoll, 2002) and self-determination theory (SDT; Deci \& Ryan, 2000). Specifically, following COR, opportunities for skill utilization may lead to skill development and learning, which in turn helps accumulate other resources that may reduce strain and improve well-being (Hobfoll, 2002). Similarly, based on SDT, we argue that skill utilization allows to satisfy the basic 
psychological needs of autonomy, relatedness, and - perhaps most importantly - competence. Satisfaction of these basic needs then serves as a nutriment to offset strain and enhance individual well-being, in just the same way that water and food are key for individuals' physical functioning (Deci \& Ryan, 2000; Van den Broeck, Vansteenkiste, De Witte, \& Lens, 2008).

In line with this reasoning, skill utilization has been shown to protect employees from psychological distress and increase well-being. For example, Van Ruysseveldt, Verboon, and Smulders (2011) found lower skill utilization to be associated with higher emotional exhaustion within a representative sample of workers in the Netherlands. Furthermore, skill utilization was shown to facilitate intrinsic motivation, job satisfaction, and work engagement, both concurrently and over time (Morrison, Cordery, Girardi, \& Payne, 2005; Ouweneel, Le Blanc, \& Schaufeli, 2011; Pousette \& Hanse, 2002).

The majority of studies on skill utilization employed between-subject research designs, focusing on the extent to which variables co-vary across individuals. Within-person research instead investigates the co-variation of variables within people over time. While betweenperson and within-person research inform each other, they are thus conceptually independent and pertain to different realities (Molenaar \& Campbell, 2009). There are good reasons to assume that skill utilization and well-being fluctuate over time, which calls for withinsubject research. For example, opportunities for skill utilization may fluctuate because most jobs include boring tasks, which provide few opportunities to use one's skills, alongside interesting tasks allowing for skill utilization (Sheldon, Turban, Brown, Barrick, \& Judge, 2003). Variations in skill utilization may also co-vary with particular circumstances such as temporary increases in workload or a shift in focus on short term productivity (Van Ruysseveldt \& Van Dijke, 2011). Employees themselves may equally create new opportunities for skill utilization, for example, when deciding to learn new skills (Fried, Hollenbeck, Slowik, Tiegs, \& Ben-David, 1999), or when proactively crafting their job (Wrzesniewski \& Dutton, 2001). Butler, Grzywacz, Bass, and Linney (2005) provide preliminary evidence that employees may experience variations in skill utilization within the same job. These authors found that $50 \%$ of the variance in skill level (a construct similar to skill utilization) was explained by within-subject variation, highlighting the utility of a within-subject design. Similarly, about $30-40 \%$ of the variance in work engagement and emotional exhaustion might be attributed to daily fluctuations (Sonnentag, Mojza, Demerouti, \& Bakker, 2012). Hence, the use of a within-subject design to study the relationship between opportunities for skill utilization and well-being seems justified and timely.

In short, between-subject research compares the well-being of employees with jobs that provide ample opportunity to use their skills, with the well-being of employees with jobs that provide little such opportunity. Complementing this perspective, this within-subject study investigates employees' well-being on a day-to-day basis: Is well-being higher on those days that employees have much opportunity to use their skills as compared to days when such opportunity is scarce? In doing so, we test whether between-person findings also extend to the within-person level. If this were true, our findings should encourage leaders and managers to create opportunities for employees to use their skills at work on a day-to-day basis. Based on the conceptual analysis and related empirical evidence from presented earlier, we predict that employees will report higher (lower) levels of well-being on days that they utilize their skills more (less) than they do on average: 
Hypothesis 1a: Daily skill utilization will positively associate with daily work engagement, so that on days when employees experience higher levels of skill utilization as compared to their baseline, they will report higher levels of work engagement.

Hypothesis $1 b$ : Daily skill utilization will negatively associate with daily emotional exhaustion, so that on days when employees experience higher levels of skill utilization as compared to their baseline, they will report lower levels of emotional exhaustion.

Although studies typically indicate that skill utilization relates positively to work engagement and negatively to emotional exhaustion, not all research confirms this view. For example, Akerboom and Maes (2006) did not find a relationship between skill utilization and emotional exhaustion among care staff members. Such inconsistencies may be caused by the presence of a moderator. Building upon SDT and P-E fit theory, we argue that work values may act as such a moderator.

\section{SDT and P-E fit explaining the moderating role of intrinsic work values}

According to SDT, two types of work values can be distinguished: intrinsic and extrinsic values (Vansteenkiste, Lens, \& Deci, 2006). Intrinsic work values include strivings for emotional intimacy, community contribution, and personal growth. Extrinsic work values, by way of contrast, pertain to achieving external signs of worth and include strivings for material benefits, financial success, status and power. According to SDT, attaching more importance to intrinsic than to extrinsic values leads to qualitatively different experiences as compared to holding predominantly extrinsic values. Whereas the predominant pursuit of intrinsic work values aligns with people's authentic growth-oriented nature, and allows them to satisfy their basic psychological needs, the pursuit of extrinsic over intrinsic values forestalls one's unconditional positive self-regard (Schmuck, Kasser, \& Ryan, 2000). This leads to stressful interpersonal comparisons (Patrick, Neighbors, \& Knee, 2004), and increases the desire to outperform others (Vansteenkiste et al., 2006).

Importantly, within SDT the relative importance people attach to intrinsic as compared to extrinsic values is considered essential. Specifically, in their seminal work, Kasser and Ryan (1996) state: "Lower psychological well-being and higher distress are predicted to occur when extrinsic aspirations and guiding principles are relatively central to an individual's personality, in comparison to intrinsic aspirations and guiding principles" (p. 281; italics added). People may indeed attach importance to different values, such as intrinsic and extrinsic ones; often a positive correlation between these sets of values is found (e.g. Vansteenkiste et al., 2007). According to SDT, the relative importance attached to intrinsic and extrinsic values is an indicator of the quality of motivation. This approach to conceptualizing motivation differs from other motivational theories. Goal setting theory (Locke \& Latham, 1990), for example, argues that setting multiple goals enhances the quantity of employee motivation. Vansteenkiste et al. (2004) provided strong evidence for the impact of the relative importance attached to intrinsic and extrinsic values. For example, these authors manipulated individuals' values in relation to a learning activity. While some held only intrinsic values, others complemented these intrinsic values with extrinsic ones. Despite the fact that both groups held equal amounts of intrinsic values, the ones pursuing intrinsic over extrinsic values outperformed the latter and experienced less stress, providing evidence for the importance of relative value pursuit. In line with these results, among employees the beneficial impact of intrinsic value pursuit is best 
observed when one's extrinsic value pursuit is taken into account: it has been shown that the pursuit of extrinsic over intrinsic work values relates negatively to job satisfaction, vitality and happiness and positively to burnout, work-family conflict and turnover-intentions (Vansteenkiste et al., 2007).

Apart from these main effects, drawing on P-E fit theory (Kristof-Brown et al., 2005), we argue that an intrinsic relative to an extrinsic value pursuit also strengthens the day-to-day association of skill utilization and psychological well-being. Following P-E fit theory, employees function best when their individual characteristics are compatible with or match the characteristics of their work environment (Kristof-Brown et al., 2005). It is particularly supply-value fit, that is to say the fit between the environmental supplies and employees' values, that has been associated in the recent past with beneficial outcomes such as job and career satisfaction, occupational commitment and performance (Resick, Baltes, \& Shantz, 2007). On the other hand, a lack of fit is presented as a precursor of burnout, which therefore is associated with various negative outcomes (Maslach, Schaufeli, \& Leiter, 2001).

Despite its central role in the P-E fit literature, relatively little research has examined supply-value fit from an objective stance (Cable \& DeRue, 2002). Most studies have adopted a subjective approach, in which employees are asked to judge the degree to which they experience a good fit with the environment (perceived fit; see Cable \& DeRue, 2002). This approach, however, has been criticized for reflecting a more general affective reaction to the workplace rather than the actual level of fit (Edwards, Cable, Williamson, Lambert, \& Shipp, 2006). Therefore, the present study follows the literature on objective fit (Cable \& Parsons, 2001), in which the individual and organizational characteristics are measured separately and the actual level of fit is calculated. Specifically, we argue that the fit between employees' predominant intrinsic work value orientation and daily opportunities for skill utilization will lead to enhanced engagement reduced levels of exhaustion. Working from the P-E fit literature, we ground this reasoning in three theoretical frameworks.

Firstly, cognitive affective personality system theory (CAPS; Mishel \& Shoda, 1995) proposes that people are sensitive to environmental aspects that fit their schemata, which are - amongst other things - shaped by their values. People are more likely to identify with environments that fit their schemata, and to experience positive emotions and enhanced motivation to perform optimally in such contexts. Specifically, drawing on CAPS, a predominant intrinsic value orientation is likely to give shape to growth-oriented schemata, and these in turn help employees to identify and use opportunities for skill utilization, which then fuels positive job related cognitions and emotions, lying at the core of engagement. Conversely, intrinsically oriented individuals may experience negative cognitions and affect in situations in which opportunities for skill utilization are lacking, as they are then hindered in realizing their aspirations. This then results in higher exhaustion levels (Maslach et al., 2001).

Secondly, the moderating role of a predominant intrinsic value orientation can also be explained with reference to Greguras and Diefendorff (2009), who advance the hypothesis that need-supplies fit fulfills one's basic needs. A predominant intrinsic value orientation (Vansteenkiste et al., 2007) and opportunities for skill utilization (Van den Broeck et al., 2008) each foster need satisfaction, which leads to the assumption that employees' basic needs are greatly satisfied (particularly when an intrinsic value orientation is matched with high levels of skill utilization), and this in turn increases their well-being. Need frustration, by way of contrast, is likely on days on which intrinsic value-oriented employees 
have few opportunities to develop their skills, and this often leads to exhaustion (Van den Broeck, Vansteenkiste, De Witte, Soenens, \& Lens, 2010).

Finally, building on COR (Hobfoll, 2002), we assume that intrinsically oriented employees, more than extrinsically oriented employees, perceive opportunities for skill utilization as resources. Fluctuations in the levels of these resources may then be reflected in fluctuations in one's well-being. Following COR, increases in resources as compared to one's baseline level set the stage for further resource development, for example, in terms of work engagement. Loss of resources or high investments that only yield modest increases in resources elicit strain, for example, in terms of exhaustion.

In support of this, previous studies that examined person-job fit in an objective manner provided evidence for the beneficial role of the interaction between employees' orientation towards intrinsic job aspects (e.g. autonomy, task variety and responsibility) and the corresponding job characteristics in terms of reduced levels of exhaustion and higher levels of engagement (Van den Broeck, Van Ruysseveldt, Smulders, \& De Witte, 2011). The current study adds to this line of work in two distinct ways. First, although Van den Broeck and colleagues (2011) relied on SDT as a theoretical framework, they measured intrinsic and extrinsic values according to Herzberg's (1968) dual structure theory. However, SDT and Herzberg's theory differ in important ways (Van den Broeck, Vansteenkiste, De Witte, Lens, \& Andriessen, 2009). Firstly, these theories tap into different aspects of individuals' value pattern: Although Herzberg focuses on how important employees consider particular job aspects, SDT moves beyond job characteristics and considers work values, which relate more closely to general life values. These theories also take a different reference point, leading to different categorizations. For example, although Herzberg considers affiliative aspects such as social support as extrinsic to one's task, SDT categorizes these as intrinsic because they align with an individual's inherent growth tendencies. Because of its theoretical relevance we rely on SDT, and therefore improve the work by Van den Broeck et al. (2011).

Secondly, this study expands the findings of Van den Broeck et al. (2011) by focusing on the cross-level interaction between individuals' value orientation and daily skill utilization. Unlike Van den Broeck et al. (2011), the current study acknowledges the importance of day-to-day variations in skill utilization and the possibility that these fluctuations may affect well-being differently for different individuals. In building on SDT and the P-E fit paradigm and following the assumption that skill-discretion and well-being may fluctuate over days, we thus propose:

Hypothesis 2a: Employees' work value orientation will moderate the positive association of daily skill utilization with daily work engagement, so that the positive relationship is stronger for employees who are predominantly intrinsically oriented.

Hypothesis 2b: Employees' work value orientation will moderate the negative association of daily skill utilization with daily emotional exhaustion, so that the negative relationship is stronger for employees who are predominantly intrinsically oriented.

\section{Method}

\section{Procedure and participants}

We approached three Belgian non-profit organizations that were likely to provide opportunities for skills utilization: a secondary school, a hospital, and a government agency. 
Data collection was introduced as part of a survey on motivation and well-being supported by the management. A total of 165 employees received a package including: (i) instructions about the completion of the surveys; (ii) a general questionnaire to measure stable characteristics; and (iii) a diary booklet to assess time-varying variables, which had to be completed for five consecutive days at the end of each working day. Confidentiality was guaranteed and a personal identification code was used to allow for linking data across time.

We used paper-and-pencil booklets, as this method gives participants without internet access the chance to participate easily, and reduces equipment and software errors. The flipside may be that time compliance is hard to control. As compliance primarily depends on participants' motivation and study design (Green, Rafaeli, Bolger, Shrout, \& Reis, 2006), we made sure management encouraged participation and designed our study so that participants had to indicate the day and time at the beginning of each daily questionnaire. All participants indicated whether they had filled out the daily questionnaire after their workday had ended.

Ninety-nine persons (response rate of 60\%) responded to the general and daily questionnaires, providing 495 usable data points. Most participants (74\%) were female. The average age was $39.7(\mathrm{SD}=10.4)$, while average tenure was 12.2 years $(\mathrm{SD}=11.1)$. $41 \%$ of the participants had a full-time job. The average working week was 34 hours $(\mathrm{SD}=12.3)$. Eight per cent of the participants occupied a management position, all of whom reported supervising less than 10 employees.

\section{Measures}

\section{General questionnaire measures}

Intrinsic and extrinsic work value orientations. These were based on the Dutch Aspiration Index (Duriez, Vansteenkiste, Soenens, \& De Witte, 2007), which was adapted to the work context. Respondents rated the importance of each of the work values on a five-point Likert scale ranging from 1 (not very important) to 5 (very important). The four items for intrinsic work values referred, for example, to having interesting work. The four items for extrinsic work values referred, for example, to having power over others. Cronbach's alphas for intrinsic and extrinsic work values were .74 and 0.80, respectively. Rather than focusing on the absolute importance of values, SDT stresses the consequences of pursuing intrinsic values over extrinsic values. Different operationalizations have been used to obtain such a relative score (see e.g. Van den Broeck et al., 2010; Vansteenkiste et al., 2007). To consistently advance the literature, we tie in with the most commonly used procedures proposed by the protagonists on intrinsic and extrinsic values (see Sheldon, Gunz, Nichols, \& Ferguson, 2010). Specifically, we computed an individual difference score by subtracting extrinsic from intrinsic values per participant (see Duriez, Soenens, \& Vansteenkiste, 2007, for a detailed description of the procedure). Theoretically, using such a difference score seems particularly valid in this study, as we wanted to account for the fact that participants often attach more importance to intrinsic than to extrinsic work values, which was also confirmed in this study $(M=4.25, \mathrm{SD}=0.61$ for intrinsic values; $M=2.01, \mathrm{SD}=0.75$ for extrinsic values). Methodologically, computing a difference score is also justified: After controlling for systematic response sets, exploratory factor analysis indicated that all intrinsic and extrinsic items loaded on one single factor, suggesting they are part of a 
single continuum. This factor explained $48 \%$ of the total variance and ranged from extrinsic values (on the negative side) to intrinsic values (on the positive side). The reliability of the composite scale was .71.

General level of well-being. General work engagement was measured using the 9-item version of the Utrecht Work Engagement Scale (UWES; Schaufeli, Bakker, \& Salanova, 2006), including items such as "At my work, I am bursting with energy".

General emotional exhaustion. This was assessed using five items such as "I feel emotionally drained from my work" of the Utrecht Burnout Scale (UBOS; Schaufeli \& Van Dierendonck, 2000). Responses were coded on a 7-point scale ranging from 0 (never) to 6 (always). Cronbach's alphas for work engagement and emotional exhaustion were .93 and .83 , respectively.

\section{Daily questionnaire measures}

Daily skill utilization. This was assessed using three items of Goudswaard, Dhondt, and Kraan (1998), which were adapted to allow for measuring day-to-day changes. A sample item is "Today, my job requires me to learn new things." Responses were given on a 5point scale ranging from 1 (completely disagree) to 5 (completely agree). Cronbach's alphas ranged from .64 to $.71(M=.68)$.

Daily well-being. Daily work engagement was assessed using UWES-9 (Schaufeli et al., 2006), while daily emotional exhaustion was measured by three items taken from the UBOS (Schaufeli \& Van Dierendonck, 2000). Items were adapted to facilitate the measurement of day-to-day changes. Example items read "At work, I felt bursting with energy today" and "I felt totally exhausted because of my work today". All items were rated on a 7-point Likert-type scale ranging from 0 (totally disagree) to 6 (totally agree). Cronbach's alphas for daily work engagement and daily exhaustion ranged from .90 to $.95(M=.92)$ and from .83 to $.91(M=.86)$, respectively.

\section{Data analyses}

Data were structured such that the measurements at the day-level (495 measurement points, Level 1) were nested within persons (99 employees, Level 2). To account for the dependent nature of the measurements at level 1, we conducted multilevel analysis using $\mathrm{R}$ version 2.13.1 (Bliese, 2013). Person-level predictor variables were centered around the grand mean, and the day-level predictor variable skill utilization was centered around the person mean to rule out interpretations referring to stable between-subjects differences (Sonnentag, Binnewies, \& Mojza, 2008).

Firstly, we estimated the unconditional means model (null model), including the intercept as the only predictor. We then tested for linear, quadratic and cubic time effects in order to characterize the functional form of work engagement and emotional exhaustion. Next, we compared a model in which the slope of time was fixed to an identical model in which the slope of time was allowed to vary across individuals. As the model fit did not significantly improve, we retained the fixed-slope model for further analyses (Model 1). We then controlled for the trait component of the respective outcome variable (Model 
2; Sonnentag et al., 2008). In Model 3, daily skill utilization was entered, together with the individual difference score reflecting intrinsic as opposed to extrinsic values which served as the moderator. Finally, in Model 4 , the skill utilization $\times$ predominant intrinsic work value orientation interaction term was added.

We estimated the models using restricted maximum likelihood estimation method (REML) to compare model fit using deviance statistics. We calculated pseudo $R^{2}$ s after each step indicating the within- and between-subject variance explained by the variables in that step (Snijders \& Bosker, 1994). The multivariate significance of effects in each step was tested by computing the increase in model fit compared with the previous step. We relied on deviance statistics ( -2 log likelihood) for comparing models that did not differ in the fixed part, and on pseudo R-square statistics where models differed in the fixed part.

\section{Results}

\section{Variability of day-level measures over time}

We started by examining within-subject and between-subject correlations and variations of the day-level measures across the five days by estimating a null model for each variable (Table 1). In total, $47 \%$ of the variance in skill utilization could be attributed to withinsubject variation, while $40 \%$ of the variance in work engagement and $38 \%$ in exhaustion was attributable to within-subject variation. Our daily main model variables were thus not stable over time but fluctuated considerably, supporting the use of multilevel analysis.

\section{Hypothesis tests}

Hypothesis 1 a stated that skill utilization would be positively related to work engagement on the daily level. As is shown in Table 2 (Model 3), daily skill utilization positively predicted daily work engagement $(B=0.25, p<.001)$, supporting Hypothesis $1 a$. Table 2 also shows that work engagement showed a cubic trend $(B=0.04, p<.05)$ over days, with an increase at the study midpoint and at the end of the study.

Hypothesis $1 b$ predicted that skill utilization would be negatively related to emotional exhaustion at the daily level. As shown in Table 3 (Model 3), daily skill utilization was not significantly related to daily emotional exhaustion $(B=-0.07, n s)$. Therefore, Hypothesis $1 b$ was not supported. From Table 3 , it can also be seen that emotional exhaustion decreased linearly over days $(B=-0.08, p<.001)$.

Hypothesis $2 a$ predicted that work value orientation would moderate the relationship between daily skill utilization and daily work engagement, so that the relationship would be stronger for predominantly intrinsic value-oriented employees. As shown in Table 2 (Model 4), Hypothesis $2 a$ was supported in that work value orientation influenced the relationship between skill utilization and work engagement $(B=0.12, p<.05)$.

As also shown in Figure 1, the simple slope test for the +1 and -1 standard deviations showed that daily skill utilization was positively related to daily work engagement for predominantly intrinsic value-oriented employees $(B=0.36, t=3.66, p<.001)$, but unrelated to work engagement for predominantly extrinsic value-oriented individuals $(B=0.13, t=$ $1.23, n s$ ). Being able to use one's skills on a daily basis turns out to be beneficial, but only for intrinsic value-oriented employees. 
Table 1. Multilevel variability estimates, between and within-subject correlations among the study variables.

\begin{tabular}{|c|c|c|c|c|c|c|c|c|c|c|c|c|c|c|c|}
\hline & & Mean & $\begin{array}{c}\text { Within } \\
\text { subject } S D\end{array}$ & $\begin{array}{l}\text { Between } \\
\text { subject } S D\end{array}$ & 1 & 2 & 3 & 4 & 5 & 6 & 7 & 8 & 9 & 10 & 11 \\
\hline \multicolumn{16}{|c|}{ Level-2 variables } \\
\hline 1 & Trait engagement & 4.30 & - & 1.00 & - & & & & & & & & & & \\
\hline 2 & Trait exhaustion & 1.30 & - & 0.97 & $-.28^{* *}$ & - & & & & & & & & & \\
\hline 3 & Intrinsic work value orientation & 4.25 & - & 0.61 & $.26^{*}$ & $-.24^{*}$ & - & & & & & & & & \\
\hline 4 & Extrinsic work value orientation & 2.01 & - & 0.75 & -.19 & .10 & -.11 & - & & & & & & & \\
\hline 5 & Intrinsic-extrinsic difference & 2.25 & - & 1.00 & $.30^{* *}$ & $-.22^{*}$ & $.67^{* *}$ & $-.80^{* *}$ & - & & & & & & \\
\hline 6 & Age & 39.70 & - & 3.22 & .12 & -.15 & .02 & -.05 & .06 & - & & & & & \\
\hline 7 & Gender $^{a}$ & 0.74 & - & 0.66 & -.05 & .11 & .10 & $-.36^{* *}$ & $.33^{* *}$ & -.07 & - & & & & \\
\hline 8 & Working hours & 29.19 & - & 3.05 & -.13 & .00 & -.11 & $.26^{*}$ & $-.25^{*}$ & $-.25^{*}$ & -.19 & - & & & \\
\hline \multicolumn{16}{|c|}{ Level-1 variables } \\
\hline 9 & Daily skill utilization & 3.40 & 0.54 & 0.57 & $.40^{* *}$ & .00 & .11 & -.03 & .08 & -.02 & -.15 & -.18 & - & $.30^{* *}$ & -.03 \\
\hline 10 & Daily work engagement & 4.06 & 0.59 & 0.73 & $.69^{* *}$ & -.18 & .09 & -.04 & .09 & .14 & -.06 & -.08 & $.47^{* *}$ & - & $-.14^{* *}$ \\
\hline 11 & Daily exhaustion & 1.18 & 0.71 & 0.91 & $-.33^{* *}$ & $.67^{* *}$ & $-.28^{* *}$ & .18 & $-.31^{* *}$ & -.17 & -.06 & .07 & .07 & -.19 & - \\
\hline
\end{tabular}

Notes: Correlations below the diagonal were computed between individuals, using each participant's mean scores for the level-1 variables. Correlations above the diagonal represent within-subject associations, and were computed by standardizing the level-1 regression coefficients for predicting one variable with the other in fixed-effects multilevel models. $N=495$ (level 1 ) and $N=99$ (level 2).

${ }^{\mathrm{a}} 0=$ Male; $1=$ Female.

${ }^{*} p<.05$ (two-tailed).

$* * 0.01$ (two-tailed) 
Table 2. Fixed-effects estimates (top) and variance-covariance estimates (bottom) for models predicting daily work engagement.

\begin{tabular}{|c|c|c|c|c|c|c|c|c|c|}
\hline & Null model & \multicolumn{2}{|c|}{ Model 1} & \multicolumn{2}{|c|}{ Model 2} & \multicolumn{2}{|c|}{ Model 3} & \multicolumn{2}{|c|}{ Model 4} \\
\hline \multicolumn{10}{|c|}{ Fixed effects (standard errors) } \\
\hline Intercept & $4.06 \quad(0.08)$ & 3.92 & $(0.09)$ & 3.92 & $(0.08)$ & 3.94 & $(0.08)$ & 3.94 & $(0.12)$ \\
\hline Time (linear) & & $0.38^{*}$ & $(0.15)$ & $0.38^{*}$ & $(0.15)$ & $0.33^{*}$ & $(0.15)$ & $0.34^{*}$ & $(0.14)$ \\
\hline Time^2 (quadratic) & & $-0.22^{*}$ & $(0.09)$ & $-0.22^{*}$ & $(0.09)$ & $-0.20^{*}$ & $(0.09)$ & $-0.20^{*}$ & $(0.09)$ \\
\hline Time^3 (cubic) & & $0.04^{*}$ & $(0.02)$ & $0.04^{*}$ & $(0.02)$ & $0.03^{*}$ & $(0.02)$ & $0.03^{*}$ & $(0.01)$ \\
\hline Trait work engagement & & & & $0.53^{* * *}$ & $(0.06)$ & $0.56^{* * *}$ & $(0.06)$ & $0.56^{* * *}$ & $(0.06)$ \\
\hline I-E value orientation & & & & & & -0.10 & $(0.06)$ & -0.10 & $(0.06)$ \\
\hline Skill utilization & & & & & & $0.24^{* * *}$ & $(0.05)$ & $0.24^{* * *}$ & $(0.05)$ \\
\hline $\begin{array}{l}\text { Skill utilization*I-E value } \\
\text { orientation }\end{array}$ & & & & & & & & $0.12^{*}$ & $(0.05)$ \\
\hline \multicolumn{10}{|l|}{ Random parameters } \\
\hline $\begin{array}{l}\text { Intercept/intercept } \\
\text { Level } 1\end{array}$ & 0.53 & \multicolumn{2}{|c|}{0.53} & \multicolumn{2}{|c|}{0.25} & \multicolumn{2}{|c|}{0.25} & \multicolumn{2}{|c|}{0.25} \\
\hline Intercept/intercept & \multirow{5}{*}{$\begin{array}{c}0.35 \\
1098.52\end{array}$} & \multicolumn{2}{|c|}{0.34} & \multicolumn{2}{|c|}{0.34} & \multicolumn{2}{|c|}{0.33} & \multicolumn{2}{|c|}{0.32} \\
\hline$-2 \times$ log likelihood & & \multicolumn{2}{|c|}{1119.01} & \multicolumn{2}{|c|}{1048.47} & \multicolumn{2}{|c|}{1033.32} & \multicolumn{2}{|c|}{1032.62} \\
\hline$\Delta-2 \times \log (d f)$ & & \multicolumn{2}{|c|}{$8.49(3)$} & \multicolumn{2}{|c|}{$58.54(1)$} & \multicolumn{2}{|c|}{$15.15(2)$} & \multicolumn{2}{|c|}{$0.70(1)$} \\
\hline Pseudo $R^{2}$ (Level-2) & & \multicolumn{2}{|c|}{$0 \%$} & \multicolumn{2}{|c|}{$45 \%$} & \multicolumn{2}{|c|}{$46 \%$} & \multicolumn{2}{|c|}{$46 \%$} \\
\hline Pseudo $R^{2}$ (Level-1) & & \multicolumn{2}{|c|}{$0 \%$} & \multicolumn{2}{|c|}{$31 \%$} & \multicolumn{2}{|c|}{$31 \%$} & \multicolumn{2}{|c|}{$31 \%$} \\
\hline
\end{tabular}

Note: Standard errors are in parentheses. $\mathrm{I}-\mathrm{E}=$ intrinsic-extrinsic.

${ }^{*} p<.05$.

${ }^{* *} p<.01$.

${ }^{* * *} p<.001$.

Hypothesis $2 b$ predicted that work value orientation would moderate the relationship between daily skill utilization and daily emotional exhaustion, so that the negative relationship would be stronger for predominantly intrinsic value-oriented employees. As shown in Table 3 (Model 4), Hypothesis $2 b$ was not supported. The relationship

Table 3. Fixed-effects estimates (top) and variance-covariance estimates (bottom) for models predicting daily emotional exhaustion.

\begin{tabular}{|c|c|c|c|c|c|c|c|c|c|}
\hline & Null model & \multicolumn{2}{|c|}{ Model 1} & \multicolumn{2}{|c|}{ Model 2} & \multicolumn{2}{|c|}{ Model 3} & \multicolumn{2}{|c|}{ Model 4} \\
\hline \multicolumn{10}{|c|}{ Fixed effects (standard errors) } \\
\hline Intercept & $1.18 \quad(0.10)$ & 1.34 & $(0.11)$ & 1.34 & $(0.08)$ & 1.33 & $(0.08)$ & 1.34 & $(0.08)$ \\
\hline Time (linear) ${ }^{\mathrm{a}}$ & & $-0.08^{* * *}$ & $(0.02)$ & $-0.08^{* * *}$ & $(0.02)$ & $-0.08^{* * *}$ & $(0.02)$ & $-0.08^{* * *}$ & $(0.02)$ \\
\hline Trait exhaustion & & & & $0.69^{* * *}$ & $(0.08)$ & $0.65^{* * *}$ & $(0.08)$ & $0.65^{* * *}$ & $(0.08)$ \\
\hline I-E value orientation & & & & & & $-0.16^{*}$ & $(0.07)$ & $-0.16^{*}$ & $(0.07)$ \\
\hline Skill utilization & & & & & & -0.07 & $(0.07)$ & -0.08 & $(0.07)$ \\
\hline $\begin{array}{l}\text { Skill utilization*I-E } \\
\text { value orientation }\end{array}$ & & & & & & & & 0.09 & $(0.07)$ \\
\hline \multicolumn{10}{|l|}{ Random parameters } \\
\hline $\begin{array}{l}\text { Intercept/intercept } \\
\text { Level } 1\end{array}$ & 0.82 & \multicolumn{2}{|c|}{0.82} & \multicolumn{2}{|c|}{0.42} & \multicolumn{2}{|c|}{0.40} & \multicolumn{2}{|c|}{0.40} \\
\hline Intercept/intercept & \multirow{5}{*}{$\begin{array}{c}0.51 \\
1289.38\end{array}$} & \multicolumn{2}{|c|}{0.49} & \multicolumn{2}{|c|}{0.49} & \multicolumn{2}{|c|}{0.49} & \multicolumn{2}{|c|}{0.49} \\
\hline$-2 \times \log$ likelihood & & \multirow{2}{*}{\multicolumn{2}{|c|}{1282.63}} & \multicolumn{2}{|c|}{1228.40} & \multicolumn{2}{|c|}{1229.33} & \multicolumn{2}{|c|}{1230.97} \\
\hline$\Delta-2 \times \log (d f)$ & & \multirow{2}{*}{\multicolumn{2}{|c|}{$\begin{array}{c}6.75(1) \\
0 \%\end{array}$}} & \multicolumn{2}{|c|}{$54.22(1)$} & \multicolumn{2}{|c|}{$0.93(2)$} & \multicolumn{2}{|c|}{$1.64(1)$} \\
\hline Pseudo $R^{2}$ (Level-2) & & & & \multicolumn{2}{|c|}{$45 \%$} & \multicolumn{2}{|c|}{$46 \%$} & \multicolumn{2}{|c|}{$46 \%$} \\
\hline Pseudo $R^{2}$ (Level-1) & & \multicolumn{2}{|l|}{$1 \%$} & \multicolumn{2}{|c|}{$32 \%$} & \multicolumn{2}{|c|}{$32 \%$} & \multicolumn{2}{|c|}{$33 \%$} \\
\hline
\end{tabular}

Note: Standard errors are in parentheses. I-E = intrinsic-extrinsic.

${ }^{a}$ The quadratic and cubic time effects were not significant and were therefore omitted from the table.

${ }^{*} p<.05$.

${ }^{* *} p<.01$.

${ }^{* * *} p<.001$. 


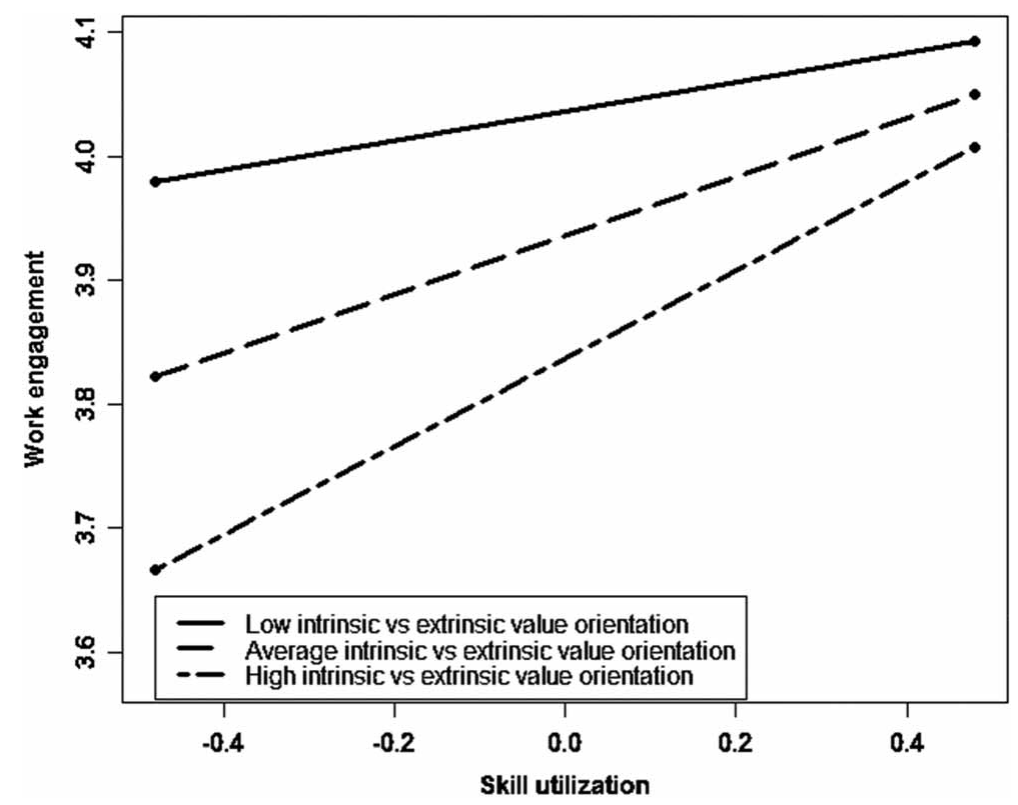

Figure 1. The moderating role of work value orientation in the relationship between skill utilization and work engagement.

between skill utilization and emotional exhaustion did not depend on employees' work value orientation $(B=0.09, n s)$.

\section{Discussion}

This diary study examined the relationship between daily skill utilization and daily wellbeing, and the impact of employees' work value orientation on this relationship. The findings suggest that daily skill utilization is positively related to daily work engagement, which is consistent with prior between-subject research (e.g. Dollard \& Bakker, 2010).

Contrary to prior between-subject research, no relationship between daily skill utilization and daily emotional exhaustion was found. This finding adds to the current debate on how job resources influence strain-related variables. For example, it aligns with recent developments in the JD-R model suggesting that job resources do not have a direct effect on strain, but only impact on strain because they buffer job demands (Bakker et al., 2014). Future studies disentangling the association between skill utilization and strain may benefit from adopting a longitudinal perspective, and incorporating crosslevel interactions and multiple mediators in an attempt to capture the complex processes that might be at play. Possibly, daily skill utilization reduces exhaustion only if exercised over longer periods of time (e.g. months not weeks) and only for some employees, or evokes different conflicting processes, which result in an overall null-effect on exhaustion. On a different note, however, it is not uncommon for between- and within-subject research to lead to different or contradictory conclusions. For example, between-subject studies showed that highly self-efficacious employees perform well, as self-efficacy promotes motivation (Sadri \& Robertson, 1993; Stajkovic \& Luthans, 1998). Within-subject studies, however, indicate that people perform less well when they become more self- 
efficacious, potentially because they become overconfident and allocate fewer resources to their tasks (Seo \& Ilies, 2009). Further analyses into when and why between-subject and within-subject analyses produce different results thus seems imperative.

With respect to value orientation, we found support for our expectation that work value orientation moderates the within-subject relationship between skill utilization and work engagement. Theoretically, we derived this expectation from integrating SDT (Deci \& Ryan, 2000) with the P-E fit perspective (Kristof-Brown et al., 2005). Our withinsubject results on work engagement support this integration and suggest that, unlike employees pursuing predominantly extrinsic values, intrinsically oriented employees who can use and develop skills on a given day will be more engaged on that day as compared to days when skill utilization is low. These results also indicate that intrinsically oriented employees are less engaged on workdays when they cannot use and develop their specific job skills. This finding seems to align with earlier research on supply-value misfit indicating the detrimental effects of misfit (see Livingstone, Nelson, \& Barr, 1997).

Notably, we employed a difference score to test our hypothesis on the relative importance of intrinsic and extrinsic values. Using a difference score is in line with the theoretical and dominant methodological approach in the realm of SDT (Sheldon et al., 2010). It also allowed us to take into account that - on average - participants attached more importance to intrinsic as compared to extrinsic values, which seems to fit with the prosocial nature of the jobs of the participants (see also Sheldon \& Krieger, 2014). This information would have gone lost if we had used the mean scores of intrinsic and extrinsic values - as done by Van den Broeck et al. (2010) to compute (three-way) interactions. Still, we acknowledge alternative means to operationalize the relative importance of intrinsic and extrinsic values, such as using a composite score of all values before including intrinsic and/or extrinsic values (Vansteenkiste et al., 2007). To consistently advance the literature on work values, future research could compare these different methods, thereby also including methodologies allowing to include both the level and relative importance of intrinsic and extrinsic values, such as polynomial regression analysis (Edwards, 2007).

\section{Strengths, limitations, and suggestions for future research}

Our study extends knowledge about the effects of value-supply fit at work, and how these effects play out at a day-to-day level. It has been more than a decade since Van Vianen (2001) called for more within-subject research to adequately test P-E fit theory, but this call has gone largely unheeded. Our study is among the first to investigate objective variations in value-supply fit from a within-subject perspective. Given that skill utilization is about using and developing skills at work, it is surprising that studies have rarely tapped into this dynamic process using within-subject designs. Our diary study reveals that $47 \%$ of the variance in skill utilization is due to within-subject variation, and that this variation is associated with work engagement on a day-to-day basis. Focusing exclusively on between-subject differences in skill utilization is thus limited. Likewise, this study adds to the growing body of research that has stressed the importance of studying daily variations in well-being.

Interestingly, our results point at changes in exhaustion and work engagement over the course of the study. As diary studies become increasingly popular, we call for more research on how well-being constructs and their relations may change over days. A 
possible research question in this respect relates to the shape of the effect and its antecedents. Future research may examine whether these time effects are caused by days of the week (e.g. Blue Monday), structural aspects (e.g. part-time work on particular days) or are method artifacts. A particular challenge in using diary designs to answer these questions is indeed that participants may get bored or become aware of the research question at hand.

Our study is subject to some limitations highlighting additional interesting areas for future research. Firstly, although we collected data over time, we cannot rule out alternative causal pathways. While conceptual work and longitudinal research suggests that skill utilization influences work engagement (e.g. Dollard \& Bakker, 2010), engaged workers might also change their work environment so that they can more fully use and develop their skills, a notion labelled job crafting. To get more definite answers on the causal direction of the association between work engagement and skill utilization, experimental and lagged research is needed.

Secondly, we relied on self-reports, which are prone to various response biases. However, by using a diary design we reduced retrospective biases. Furthermore, we eliminated common method bias by person-mean centering our daily measures, assessing work value orientations and skill utilization via different questionnaires and at different time points, and testing for cross-level interactions. These measures rule out the possibility that the interaction effect we found in our study is completely due to common-method bias (Siemsen, Roth, \& Oliveira, 2010). Nonetheless, multisource research would be beneficial for confirming our findings. Alternatively, future research may benefit from separating the assessment of the variables under study in time by measuring skill utilization during the work day and well-being in the evening (e.g. just before leaving one's workplace).

Thirdly, another promising avenue for future research is to combine field studies with experimental studies because field studies, while having important merits for organizations, may suffer from restriction of range. For instance, Schneider (1983) argued that in most real work settings extreme mismatches between individual characteristics of employees and their job hardly exist because employees self-select into organizations and tend to leave when experiencing extreme misfit. This may result in a restriction of range, which limits the possibilities of finding significant interaction effects.

Finally, while different types of P-E fit exist, we only investigated value-supply fit in this study. It is possible that different types of fit (e.g. demands-abilities fit, value-supply fit) have differential effects on well-being at work (Taris \& Feij, 2001). It may also be that different types of fit interactively influence well-being. Hence, it seems critical for researchers to investigate how the association of supply-value fit and work engagement changes when, for example, controlling for demands-abilities fit.

\section{Practical implications}

Our findings offer valuable practical insights for human resource managers and employees. We focused on skill utilization, a focal human resource practice that aims to increase the use of employees' skills. The improvement of skill utilization has been advanced as part of high-involvement human resource practices that alter job design and may stimulate employees' well-being in the organization (McClean \& Collins, 2011). Skill utilization 
was shown to directly relate to employees' well-being on any given work day. Thus, organizations need to continuously provide employees with opportunities to use and develop their skills in order to keep them engaged at work. Notably, employees scoring high on intrinsic work value orientation, more so than extrinsically oriented employees, appeared to be less engaged on days when their skill utilization was low. Organizations should therefore pay particular attention to intrinsically value-oriented employees on those days where work constraints make it difficult for employees to continuously use and develop their skills.

From a personnel selection view, one could recommend that selection decisions are based on the fit between the values of the applicants and the opportunities for skill utilization, which are likely available on a daily basis. Conversely, employees pursuing intrinsic values over extrinsic values might also approach a new working environment by especially seeking particular job characteristics that assure skill utilization. For organizations, it would then be beneficial to offer special arrangements of job characteristics that help attract such candidates and to keep them engaged. The current results attest to the importance of human resource practices such as the improvement of skill utilization, since skill utilization is imperative to predicting work engagement.

\section{Acknowledgements}

We would like to thank Jolien Nuelens and Jolien Philipsen for their assistance in data collection We would like to dedicate this article to Willy Lens, who provided opportunities to use our skills on a daily base.

\section{Disclosure statement}

No potential conflict of interest was reported by the authors.

\section{References}

Akerboom, S., \& Maes, S. (2006). Beyond demand and control: The contribution of organizational risk factors in assessing the psychological well-being of health care employees. Work \& Stress, 20, 21-36.

Bakker, A. B., Demerouti, E., \& Sanz-Vergel, A. I. (2014). Burnout and work engagement: The JD-R approach. Annual Review of Organizational Psychology and Organizational Behavior, 1, 389-411.

Bliese, P. (2013). Multilevel modeling in R (2.5). Retrieved from http://cran.r-project.org/doc/ contrib/Bliese_Multilevel.pdf

Bolger, N., Davis, A., \& Rafaeli, E. (2003). Diary methods: Capturing life as it is lived. Annual Review of Psychology, 54, 579-616.

Butler, A., Grzywacz, J., Bass, B., \& Linney, K. (2005). Extending the demands-control model: A daily diary study of job characteristics, work-family conflict and work-family facilitation. Journal of Occupational and Organizational Psychology, 78, 155-169.

Cable, D. M., \& DeRue, D. S. (2002). The convergent and discriminant validity of subjective fit perceptions. Journal of Applied Psychology, 87, 875-884.

Cable, D. M., \& Parsons, C. K. (2001). Socialization tactics and person-organization fit. Personnel Psychology, 54, 1-23.

Deci, E. L., \& Ryan, R. M. (2000). The "what" and "why" of goal pursuits: Human needs and the selfdetermination of behavior. Psychological Inquiry, 11, 227-268. 
Demerouti, E., Bakker, A. B., Nachreiner, F., \& Schaufeli, W. B. (2001). The job demands-resources model of burnout. Journal of Applied Psychology, 86, 499-512.

Dollard, M. F., \& Bakker, A. B. (2010). Psychosocial safety climate as a precursor to conducive work environments, psychological health problems, and employee engagement. Journal of Occupational and Organizational Psychology, 83, 579-599.

Duriez, B., Vansteenkiste, M., Soenens, B., \& De Witte, H. (2007). The social costs of extrinsic relative to intrinsic goal pursuits: Their relation with social dominance and racial and ethnic prejudice. Journal of Personality, 75, 757-782.

Edwards, J. R. (2007). Alternatives to difference scores. Polynomial regression analysis and response surface methodology. In C. Ostroff and T. A. Judge (Eds.), Perspectives on organizational fit (pp. 361-372). San Francisco, CA: Jossey-Bass.

Edwards, J. R., Cable, D. M., Williamson, I. O., Lambert, L. S., \& Shipp, A. J. (2006). The phenomenology of fit: Linking the person and environment to the subjective experience of personenvironment fit. Journal of Applied Psychology, 91, 802-827.

Fried, Y., Hollenbeck, J. R., Slowik, L. H., Tiegs, R. B., \& Ben-David, H. A. (1999). Changes in job decision latitude: The influence of personality and interpersonal satisfaction. Journal of Vocational Behavior, 54, 233-243.

Goudswaard, A., Dhondt, S., \& Kraan, K. (1998). Flexibility and work in the information society Questionnaire for employees in companies involved in the SZW-Werkgeverspanel 1998 [in Dutch]. Hoofddorp: TNO Arbeid.

Green, A. S., Rafaeli, E., Bolger, N., Shrout, P. E., \& Reis, H. T. (2006). Paper or plastic? Data equivalence in paper and electronic diaries. Psychological Methods, 11, 87-105.

Greguras, G. J., \& Diefendorff, J. M. (2009). Different fits satisfy different needs: Linking personenvironment fit to employee commitment and performance using self-determination theory. Journal of Applied Psychology, 94, 465-477.

Hausser, J. A., Mojzisch, A., Niesel, M., \& Schulz-Hardt, S. (2010). Ten years on: A review of recent research on the Job Demand-Control (-Support) model and psychological well-being. Work and Stress, 24, 1-35.

Herzberg, F. (1968). Work and the nature of man. London: Crosby.

Hobfoll, S. E. (2002). Social and psychological resources and adaptation. Review of General Psychology, 6, 307-324.

Karasek, R. A. (1979). Job demands, job decision latitude and mental strain: implications for job redesign. Administrative Science Quarterly, 24, 285-308.

Kasser, T., \& Ryan, R. M. (1996). Further examining the American dream: Differential correlates of intrinsic and extrinsic goals. Personality and Social Psychology Bulletin, 22, 280-287.

Kristof-Brown, A. L., Zimmerman, R. D., \& Johnson, E. C. (2005). Consequences of individuals' fit at work: A meta-analysis of person-job, person-organization, person-group, and person-supervisor fit. Personnel Psychology, 58, 281-342.

Livingstone, L. P., Nelson, D. L., \& Barr, S. H. (1997). Person-environment fit and creativity: An examination of supply-value and demand-ability versions of fit. Journal of Management, 23, 119-146.

Locke, E. A., \& Latham, G. P. (1990). A theory of goal setting and task performance. Englewood Cliffs, NJ: Prentice Hall.

McClean, E., \& Collins, C. J. (2011). High-commitment HR practices, employee effort, and firm performance: Investigating the effects of HR practices across employee groups within professional services firms. Human Resource Management, 50, 341-363.

Maslach, C., Schaufeli, W., \& Leiter, M. (2001). Job burnout. Annual Review of Psychology, 52, 397-422.

Michel, W., \& Shoda, Y. (1995). A cognitive-affective system theory of personality: Reconceptualizing situations, dispositions, dynamics, and invariance in personality structure. Psychological Review, 102, 246-268.

Molenaar, P. C., \& Campbell, C. G. (2009). The new person-specific paradigm in psychology. Current Directions in Psychological Science, 18, 112-117. 
Morrison, D., Cordery, J., Girardi, A., \& Payne, R. (2005). Job design, opportunities for skill utilization, and intrinsic job satisfaction. European Journal of Work and Organizational Psychology, 14, 59-79.

Ohly, S., Sonnentag, S., Niessen, C., \& Zapf, D. (2010). Diary Studies in Organizational Research. Journal of Personnel Psychology, 9, 79-93.

Ouweneel, E., Le Blanc, P. M., \& Schaufeli, W. B. (2011). Flourishing students: A longitudinal study on positive emotions, personal resources, and study engagement. The Journal of Positive Psychology, 6, 142-153.

Patrick, H., Neighbors, C., \& Knee, C. R. (2004). Appearance-related social comparisons: The role of contingent self-esteem and self-perceptions of attractiveness. Personality and Social Psychology Bulletin, 30, 501-514.

Pousette, A., \& Hanse, J. J. (2002). Job characteristics as predictors of ill-health and sickness absenteeism in different occupational types- a multigroup structural equation modelling approach. Work \& Stress, 16, 229-250.

Resick, C. J., Baltes, B. B., \& Shantz, C. W. (2007). Person-organization fit and work-related attitudes and decisions: Examining interactive effects with job fit and conscientiousness. Journal of Applied Psychology, 92, 1446-1455.

Sadri, G., \& Robertson, I. T. (1993). Self-efficacy and work-related behavior: A review and metaanalysis. Applied Psychology: An International Review, 42, 139-152.

Schaufeli, W. B., \& Bakker, A. B. (2004). Job demands, job resources, and their relationship with burnout and engagement: a multi-sample study. Journal of Organizational Behavior, 25, 293-315.

Schaufeli, W. B., Bakker, A. B., \& Salanova, M. (2006). The measurement of work engagement with a short questionnaire: A cross-national study. Educational and Psychological Measurement, 66, 701-716.

Schaufeli, W. B., \& Van Dierendonck, D. (2000). UBOS: Utrecht burnout Scale manual [in Dutch]. Utrecht: Swets Test Services.

Schmuck, P., Kasser, T., \& Ryan, R. (2000). Intrinsic and extrinsic goals: Their structure and relationship to well-being in German and U.S. college students. Social Indicators Research, 50, 225-241.

Schneider, B. (1983). Interactional psychology and organizational behavior. Research in Organizational Behavior, 5, 1-31.

Seo, M. G., \& Ilies, R. (2009). The role of self-efficacy, goal, and affect in dynamic motivational selfregulation. Organizational Behavior and Human Decision Processes, 109, 120-133.

Sheldon, K. M., Gunz, A., Nichols, C. P., \& Ferguson, Y. (2010). Extrinsic value orientation and affective forecasting: overestimating the rewards, underestimating the costs. Journal of Personality, 78, 149-78.

Sheldon, K. M., \& Krieger, L. S. (2014). Walking the talk: Value importance, value enactment, and well-being. Motivation and Emotion, 38, 609-619.

Sheldon, K., Turban, D., Brown, K., Barrick, M., \& Judge, T. (2003). Applying self-determination theory to organizational research. Research in Personnel and Human Resources Management, 22, 357-393.

Siemsen, E., Roth, A., \& Oliveira, P. (2010). Common method bias in regression models with linear, quadratic, and interaction effects. Organizational Research Methods, 13, 456-476.

Snijders, T. A. B., \& Bosker, R. J. (1994). Modeled variance in two-level models. Sociological Methods \& Research, 22, 342-363.

Sonnentag, S., Binnewies, C., \& Mojza, E. J. (2008). “Did you have a nice evening?" A day-level study on recovery experiences, sleep, and affect. Journal of Applied Psychology, 93, 674-684.

Sonnentag, S., Mojza, E. J., Demerouti, E., \& Bakker, A. B. (2012). Reciprocal relations between recovery and work engagement: the moderating role of job stressors. Journal of Applied Psychology, 97, 842-853.

Stajkovic, A. D., \& Luthans, F. (1998). Self-efficacy and work-related performance: A meta analysis. Psychological Bulletin, 124, 240-261. 
Taris, R., \& Feij, J. (2001). Longitudinal examination of the relationship between supplies-values fit and work outcomes. Applied Psychology, 50, 52-80.

Van den Broeck, A., Van Ruysseveldt, J., Smulders, P., \& De Witte, H. (2011). Does an intrinsic work value orientation strengthen the impact of job resources? A perspective from the Job demands-resources model. European Journal of Work and Organizational Psychology, 20, 581-609.

Van den Broeck, A., Vansteenkiste, M., De Witte, H., \& Lens, W. (2008). Explaining the relationships between job characteristics, burnout and engagement: The role of basic psychological need satisfaction. Work \& Stress, 22, 277-294.

Van den Broeck, A., Vansteenkiste, M., De Witte, H., Lens, W., \& Andriessen, M. (2009). Self-determination theory: About the quality of work motivation. Gedrag \& Organisatie, 22, 316-334.

Van den Broeck, A., Vansteenkiste, M., De Witte, H., Soenens, B., \& Lens, W. (2010). Capturing autonomy, competence, and relatedness at work: Construction and initial validation of the Work-related basic need satisfaction scale. Journal of Occupational and Organizational Psychology, 83, 981-1002.

Van den Broeck, A., Vansteenkiste, M., Lens, W., \& De Witte, H. (2010). Unemployed individuals' work values and job flexibility: An explanation from expectancy-value theory and self-determination theory. Applied Psychology, 59, 296-317.

Van Ruysseveldt, J., \& van Dijke, M. (2011). When are workload and workplace learning opportunities related in a curvilinear manner? The moderating role of autonomy. Journal of Vocational Behavior, 79, 470-483.

Van Ruysseveldt, J., Verboon, P., \& Smulders, P. (2011). Job resources and emotional exhaustion: The mediating role of learning opportunities. Work \& Stress, 25, 205-223.

Vansteenkiste, M., Lens, W., \& Deci, E. L. (2006). Intrinsic versus extrinsic goal contents in selfdetermination theory: Another look at the quality of academic motivation. Educational Psychologist, 41, 19-31.

Vansteenkiste, M., Neyrinck, B., Niemiec, C. P., Soenens, B., De Witte, H., \& Van den Broeck, A. (2007). On the relations among work value orientations, psychological need satisfaction and job outcomes: A self-determination theory approach. Journal of Occupational and Organizational Psychology, 80, 251-277.

Vansteenkiste, M., Simons, J., Lens, W., Soenens, B., Matos, L., \& Lacante, M. (2004). Less is sometimes more: Goal content matters. Journal of Educational Psychology, 96, 755-764.

Van Vianen, A. (2001). Person-organisation fit: The match between theory and methodology: Introduction to the special issue. Applied Psychology, 50, 1-4.

Wrzesniewski, A., \& Dutton, J. E. (2001). Crafting a job: Revisioning employees as active grafters of their work. Academy of Management Review, 26, 179-201. 